\title{
RELAÇÕES DA DISTRIBUIÇÃO DE FEIÇÕES GRAVITACIONAIS E FEIÇÕES EROSIVAS NA CUESTA DA SERRA GERAL COM PROCESSOS NATURAIS E ANTROPICOS: RESULTADOS PRELIMINARES
}

\author{
Helena Gladis Bozzo Moreira ${ }^{(a)}$, Luiz Felipe Soares Cherem $^{(b)}$, Isabela Braichi Pôssas ${ }^{(c)}$ \\ (a) Departamento Ciências Ambientais - Instituto de Estudos Socioambientais, Universidade Federal de Goiás - \\ helenagbmoreira@gmail.com \\ (b) Departamento Geografia - Instituto de Estudos Socioambientais, Universidade Federal de Goiás - \\ luis.cherem@gmail.com \\ (c) Departamento de Geografia - Instituto de Estudos Socioambientais, Universidade Federal de Goiás - \\ isabelabraichi@gmail.com
}

EIXO: SISTEMAS GEOMÓRFOLOGICOS: ESTRUTURA, DINÂMICAS E PROCESSOS.

\section{Resumo}

A Serra Geral, por volta da década de 80 , começou a sofrer um grande avanço da agricultura extensiva no Chapadão do Oeste Baiano, o que fez com que essa ficasse mais vulnerável as atividades erosivas. As erosões fazem parte dos processos morfogenéticos, o que resulta em uma evolução da paisagem. Esse mapeamento visa favorecer o conhecimento da morfologia da Serra Geral. A análise das imagens de satélite possibilitou a identificação das feições erosivas e quais processos são responsáveis pelo aparecimento dessas feições.

Palavras chave: Serra Geral de Goiás e Tocantins. erosões. morfologia.

\section{Introdução}

A borda ocidental do Chapadão Oeste da Bahia corresponde uma cuesta denominada Serra Geral de Goiás e Tocantins, que segue por cerca de $400 \mathrm{~km}$ ao longo da divisa da Bahia com os estados que dão nome a feição. A Serra Geral é uma feição cuja evolução se deve, predominantemente, às custas de erosão regressiva (IBGE, 2009; GOUDIE, 2006), sendo observados inúmeros morros testemunhos que atestam a favor dessa teoria (Mauro et al., 1982). Recentemente, Zancopé et al. (2013) avaliaram a atividade erosiva de inúmeros feições que indicam o processo erosivo acelerado e movimentos de massa ao longo dessa cuesta, cuja gênese atual estaria associada a ocupação do Chapadão Central até sua borda, sem respeito a legislação ambiental, conforme apontam os autores. Na região centro-sul dessa cuesta, próximo ao município de Posse (GO) foi verificado que, entre 1990 e 2014 a ocupação da Chapada pouco tem influenciado o início dos processos de degradação do relevo, predominando o controle de intensos eventos de chuva (ROSA et al., 2017). Um estudo realizado no trecho extremo norte da cuesta afirma, por sua vez, que a agricultura é um fator que intensifica esses processos (ALVES et a., 2016). 
A chapada está sobre forte pressão antrópica desde o final da década de 1980, quando se deu o início da ocupação do Oeste da Bahia (MENKE et al, 2009), já estando completamente ocupada em 2013 (MENDES, 2008; BRASIL, 2015). Em contrapartida, toda a extensão do lado ocidental desse limite é acompanhada por diversas unidades de conservação nos estados de Goiás e Tocantins, tendo uma lenta sucessão de uso e cobertura do solo (ALMEIDA, 2012; TOCANTINS, 2012; SANTOS e NUNES, 2015). Assim, esse limite corresponde a uma região de contato de diferentes unidades socioambientais, a oeste menos alterada e a leste mais alterada.

O objetivo do trabalho é identificar e mapear as feições gravitacionais e feições erosivas existentes em toda a extensão da Serra Geral de Goiás e Tocantins para contribuir na avaliação da variação espacial dos fatores controladores (naturais e antrópicos) no recuo da escarpa.

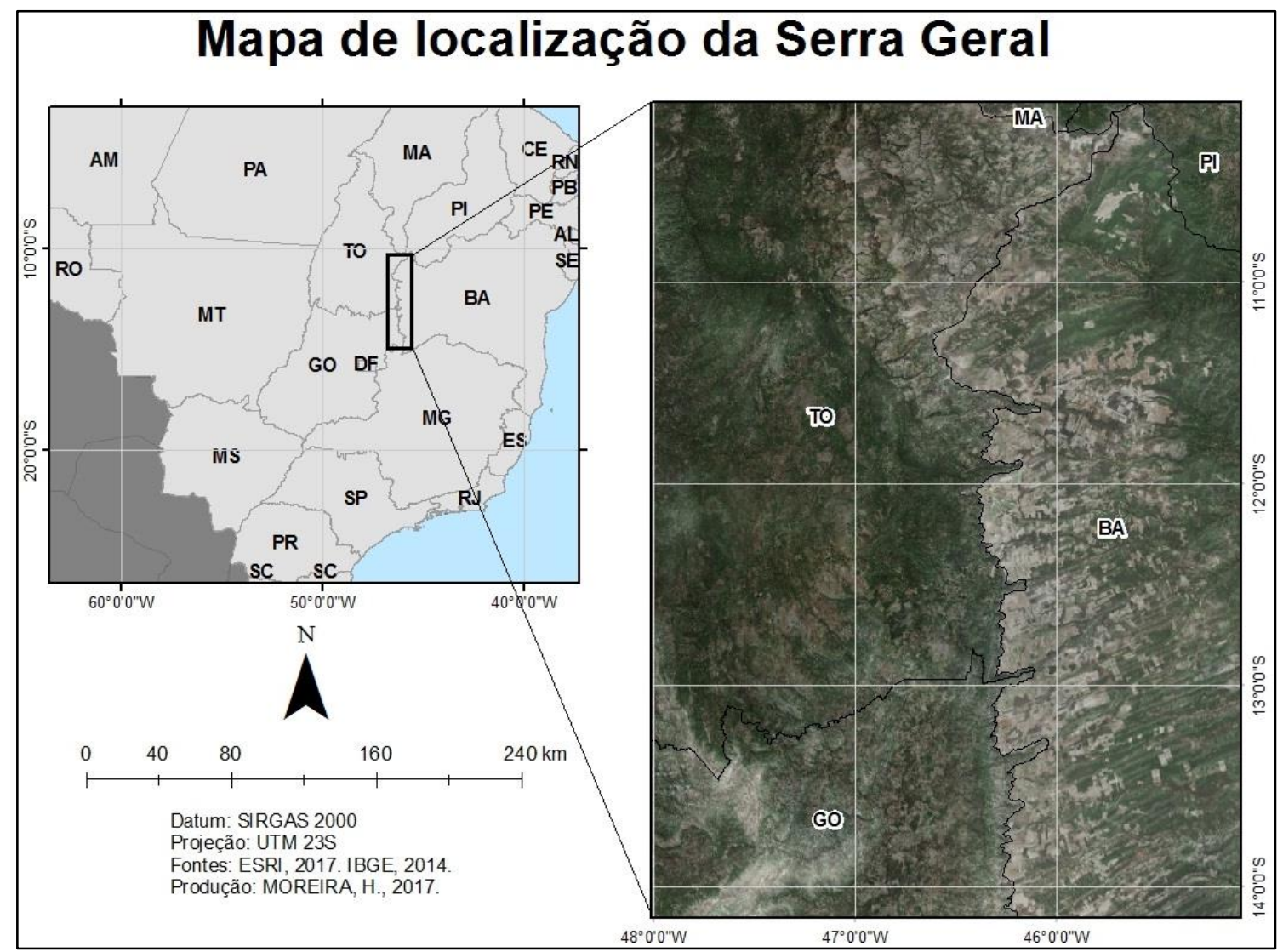

Figura 1 - localização da área de estudo no Brasil (esquerda) e identificação da cuesta da Serra Geral de Goiás e Tocantins (direita) 


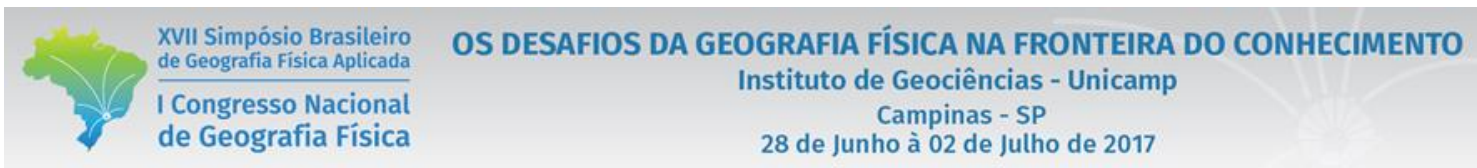

\section{Materiais e Métodos}

Os procedimentos metodológicos utilizados neste trabalho consistiram na elaboração de um banco de dados composto pela geologia e geomorfologia obtidas do site "Infraestrutura Nacional de Dados Espaciais - INDE", também pela drenagem colhida na ferramenta hidroweb do site da Agência Nacional das Águas - ANA. Posteriormente, utilizou-se a imagem de satélite de alta resolução disponibilizada pela ferramenta basemap no software ArcGis, para a identificação preliminar dos movimentos de massa e feições erosivas. Essa identificação ocorreu a "olho nu" na escala 1:10.000.

\section{Discussão}

As atividades erosivas que acarretam esse relevo de cuesta são fundamentais para a evolução da paisagem. Foram identificadas erosões por toda a extensão (N-S) da Serra Geral o que possibilitou perceber uma dinâmica de distribuição das feições gravitacionais e feições erosivas.

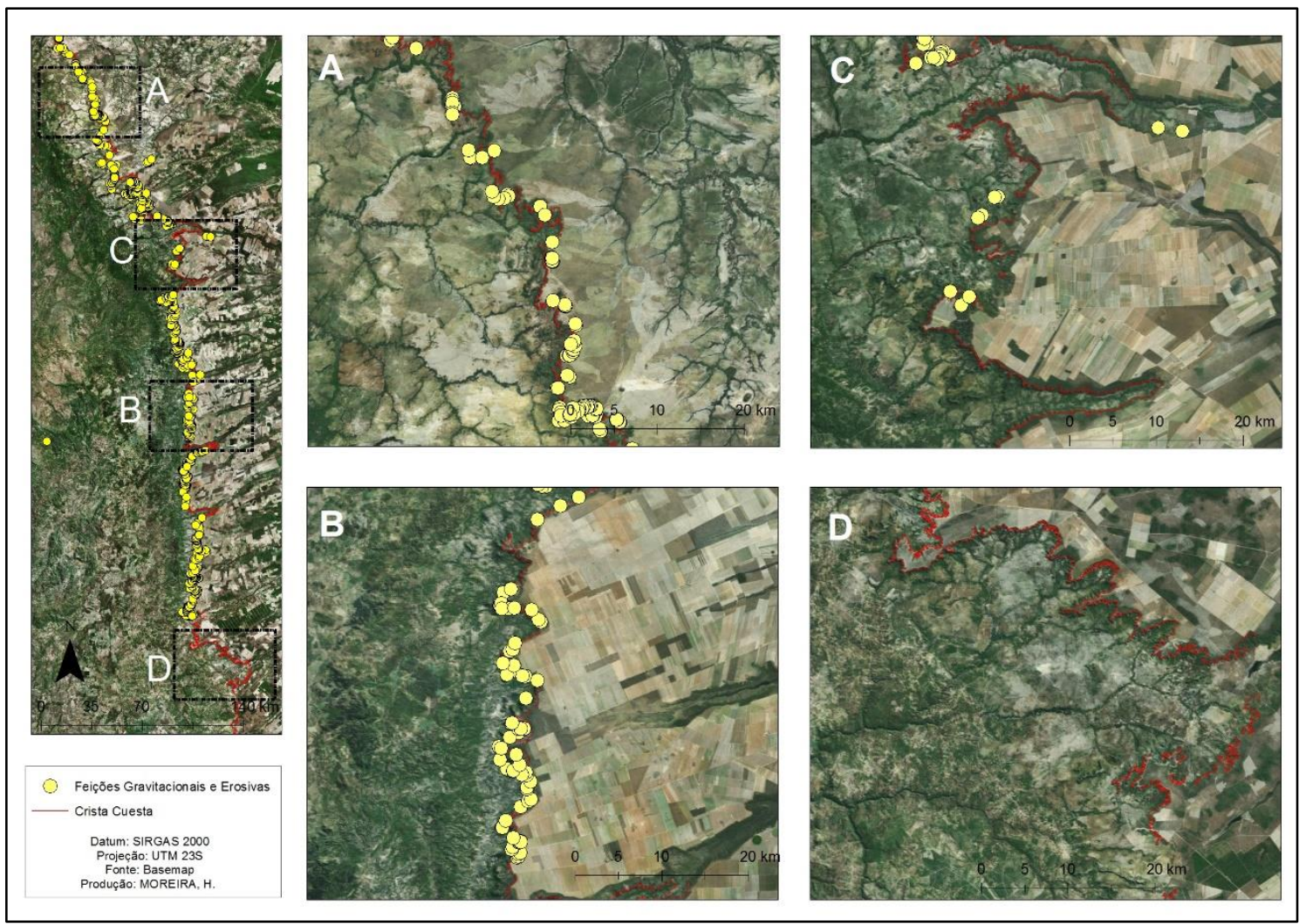

Figura 2 - Localização e identificação das áreas representativas sobre a sinuosidade da cuesta e das distribuição das feições mapeadas (esquerda); trechos mais retilineo da cuesta com maior concentração de feições erosivas e gravitacionais (A e B), trecho mais sinuoso da cuesta cm menor concetração de feições erosivas e gravitacionais (C e D). 
Essa distribuição ocorre de forma concentrada em pontos específicos da cuesta o que é possível perceber na figura anterior. Nota-se que onde essas feições gravitacionais e erosivas estão concentradas (A e B) a crista da cuesta se encontra retilínea. Já as áreas com pouca incidência de feições gravitacionais e erosivas (C e D), a crista da cuesta se encontra muito sinuosa. A variação dessa sinuosidade ao longo da Serra Geral, ocorre pelas diferentes intensidades das atividades erosivas em cada ponto.

Relacionando esses elementos à proposta de dinâmica de grandes escarpamentos de Matmon (2002), os trechos da cuesta que apresentam maior sinuosidade e ausência de feições erosivas ou gravitacionais seriam os mais estáveis por já estarem em um estado de recuo avançado. Dessa forma, é possível perceber que a dinâmica de distribuição dessas feições contém uma relação com o estado de avanço da crista.

\section{Considerações Finais}

Após a realização dos procedimentos metodológicos, foi possível observar a dinâmica da distribuição das feições gravitacionais e as feições erosivas na Serra Geral, identificando assim, o processo de regressão da escarpa da Serra Geral.

O trabalho possibilitou compreender os processos erosivos que ocorrem na cuesta da Serra Geral, podem estar associados às atividades antrópicas que ocorrem no Chapadão do Oeste baiano, ou podem estar associados a fragilidade natural do relevo em que possui uma predisposição natural e uma declividade acidentada (ZANCOPÉ et. al 2013; GOUDIE, 2004). Por se tratar de um trabalho preliminar, serão realizados estudos mais aprofundados em relação a dinâmica da formação da paisagem e dos processos associados ao recuo da cuesta. Mesmo com os resultados preliminares, ressalta-se a importância do trabalho na contribuição na formação de políticas voltadas para o controle das atividades que podem intensificar os processos erosivos ao longo da Serra Geral.

\section{Bibliografia}

ALMEIDA, L. B. Zoneamento Geoambiental do Estado do Tocantins. Universidade Estadual de São Paulo. Campus Rio Claro, 2012.

ALVES, V. A., COSTA, D.H., ALVES, R.R. Identificação e avaliação de processos erosivos através de imagens LANDSAT 5 / 8 e DRONE. IN: Simpósio Nacional de Geomorfologia, 11, Maringá, 2016. 
BORGES, E. F.; SANO, E.E. Series temporais de EVI do Modis para o mapeamento de uso e cobertura vegetal do Oeste da Bahia. Boletim Cienc. Geod., Curitiba, v. 20, n. 3, p. 526-547, set/2014.

GOUDIE, A, S. Encyclopedia of Geomorphology. Routledge: London, 2004.

MATMON, A., BIERMAN, P., ENZEL,Y. Patern and tempo of great escarpment erosion. Geology, v. 30, p. 1135-1138. Dez/2002.

MENKE, A. B; et al. Analise das mudanças do uso agrícola da terra a partir de dados de sensoriamento remoto multi-temporal no município de Luis Eduardo Magalhães (BA- Brasil). Soc. Nat. (online), Uberlândia, v. 21, n. 3, p. 315-326, dez/2009.

MOURA, J. R. S. Quaternário: período de transformações ambientais recentes. Org. Antônio Jose Teixeira Guerra e Sandra Baptista da Cunha. Geomorfologia: uma atualização de bases e conceitos. 1995, 2a edição, 335 $364 p$.

ROSA, L.E.; FARIA, K. M. S.; CHEREM, L. F. S.; NUNES, E. Analise da mudança da cobertura e uso entre 1990 e 2014 nas zonas de amortecimento das unidades de conservação do Parque Estadual de Terra Ronca e Área de Proteção Ambiental Serra Geral de Goiás. In: XVI Simpósio Brasileiro de Geografia Física Aplicada, 2015, Terezina. Anais do XVI Simpósio Brasileiro de Geografia Física Aplicada, 2015, p. 3686-3693.

SANO, E. E. et al. Mapeamento semidetalhado do uso da terra do Bioma Cerrado. Pesquisa Agropecuária Brasileira, Brasília, v. 43, n. 1, p. 153-156, jan/2008.

SANTOS, S. A.; NUNES, F. G. Mapeamento do conflito de uso legal da terra nas unidades de conservação (UCs) da Reserva da Biosfera do Cerrado: nordeste de Goiás. In: XVII SBSR - Simposio Brasileiro de Sensoriamento Remoto, 2015, Joao Pessoa - PB. Anais do XVII Simposio Brasileiro de Sensoriamento Remoto - SBSR. São Jose dos Campos, SP: MCT/INPE, 2015, v. 1, p. 933-940.

SUMMERFIELD, M. A. Global Geomorphology. Wiley and sons: London. 1991. 547p.

TOCANTINS. Secretária do Planejamento e da Modernização da Gestão Pública (SEPLAN). Estado do Tocantins - Áreas de Uso Legal Restrito e Potenciais à Conservação Ambiental - Tabelas e Mapas Síntese. Palmas: SEPLAN/DZE, 2012. 44p.

ZANCOPE, M. H. C.; MOMOLI, R. S.; BAYER, M. Movimentos de massa nas nascentes do Rio São Vicente, Parque Estadual de Terra Ronca. Relatório Técnico: UFG/IESA/LABOGEF, 2013. 